\title{
Free Prostate Specific Antigen Measurement
}

National Cancer Institute

\section{Source}

National Cancer Institute. Free Prostate Specific Antigen Measurement. NCI Thesaurus.

Code C132383.

The determination of the amount of free prostate specific antigen in a biological sample. 